\title{
A REVIEW: THIAZINES DERIVATIVES TREATED AS POTENTIAL ANTIMICROBIAL AGENTS
}

\author{
PRAVEEN KUMAR SHARMA*, REENA MAKKAR
}

Department of Chemistry, School of Physical Science, Lovely Professional University, Phagwara, Punjab, India. Email: pk_pandit1982@yahoo.com

Received: 30 September 2016, Revised and Accepted: 12 October 2016

\section{ABSTRACT}

In recent days, heterocycles and their derivatives have become strong reflection in medicinal research and pharmaceutical fields because of their practical pharmacological and biological activities. Organic compounds; mainly heterocyclic compounds are wealthy in natural world and contain extra value because their structural subunits are established in many natural products such as enzymes, vitamins, antibiotics, acids, and hormones. Thiazine nucleuses found in compounds have variety of pharmacological activities such as antitumor, antimicrobial, antibacterial, antifungal, antiviral, and anti-inflammatory. This review spotlight on the substituted thiazines with possible antimicrobial activities that are at the present in development.

Keywords: Antibacterial, Substituted thiazines, Antimicrobial agents.

(C) 2017 The Authors. Published by Innovare Academic Sciences Pvt Ltd. This is an open access article under the CC BY license (http://creativecommons. org/licenses/by/4. 0/) DOI: http://dx.doi.org/10.22159/ajpcr.2017.v10i1.15467

\section{INTRODUCTION}

Heterocycles participate in a remarkably important section in the present civilization and group of different applications in diverse fields. Thus, continuously research work has been carried out for the synthesis of new heterocyclic compounds counting synthesis of derivatives of naturally finding ones - proteins, nucleic acids, alkaloids, vitamins, etc. Heterocycles mainly containing heteroatom nitrogen and sulfur have immense possible effect primarily as agrochemicals, medicinal drugs, etc. Thiazine based heterocyclic compound in which $\mathrm{N}$ and $\mathrm{S}$ atom present in different position (Fig. 1) having N-C-S, N-C, and C-S relationship have been used as antitubercular, antibacterial, antimicrobial, antitumor, antifungal, herbicidal agents, tranquilizers and different dyes, etc. Thus, substituted thiazines are employed in a diversity of organic reactions as reactant, intermediates, and products [1-11]. Thus, the article is dedicated to the place of different thiazine ring systems in heterocycles for their nature as antimicrobial agents. The objective of this review is gather data on antimicrobial activities of thiazines derivatives. This review has clearly confirmed that substituted thiazines treated as potential antimicrobial agents. Thus, we have decided to review on different form of substituted thiazines.

\section{BIOLOGICAL ACTIVITY OF 1,4-BENZOTHIAZINE}

Ali and El-Kazak (2015): Thiazine derivatives (1) were evaluated in vitro for their antimicrobial activity and showed fair results as antimicrobial agents [12].

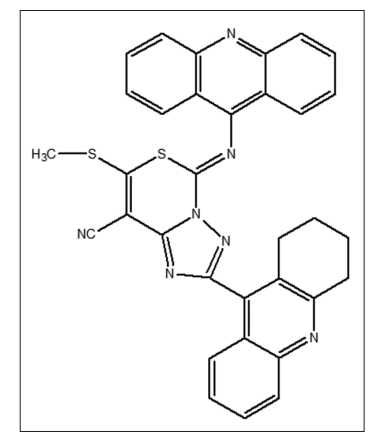<smiles>C1=CNSC=C1</smiles>

1,2-Thiazine<smiles>C1=CN=CSC1</smiles>

1,3-Thiazine<smiles>C1=CSC=CN1</smiles>

$\mathrm{H}$
Fig. 1: Different type of thiazines based on position of $\mathrm{N}$ and $\mathrm{S}$ atoms

Rathod and Rajput (2010): Synthesized thiazine derivatives were examined for their antimicrobial activities against Staphylococcus aureus, Bacillus subtilis, Pseudomonas aeruginosa, and Escherichia coli species. The presence of $-\mathrm{OH}$ group and $\mathrm{N}, \mathrm{S}$, hetero atoms add to the antimicrobial activity of this compound [13].

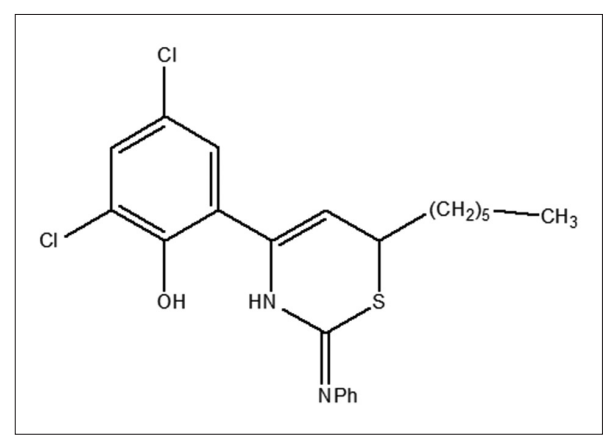

Shweta and Deepika (2011): Synthesized compound was evaluated for antibacterial and antif ungal activities against B. subtilis, E. coli, etc., and showed antibacterial activity [14]. 


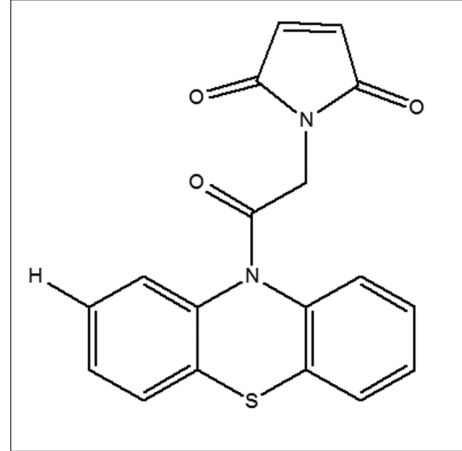

Deshmukh (2015): 1,3-thiazines when monitor in vitro against some general bacteria, viz., E. coli, S. aureaus, B. subtilis, and P. argenosa. It was found that compounds have shown a range of biological activities [15].

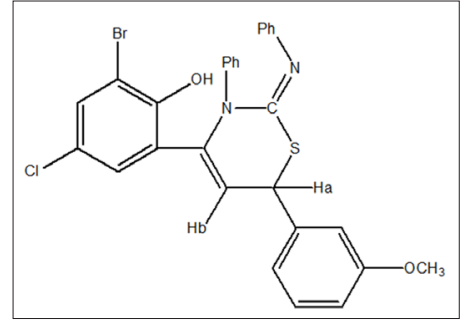

Babu and Pitchai (2015): The synthesized thiazine derivatives were elucidated using spectral data and antimicrobial activity studied using disc diffusion method E. coli, S. aureus, Aspergillus niger, and consider as good antimicrobial agents [16].

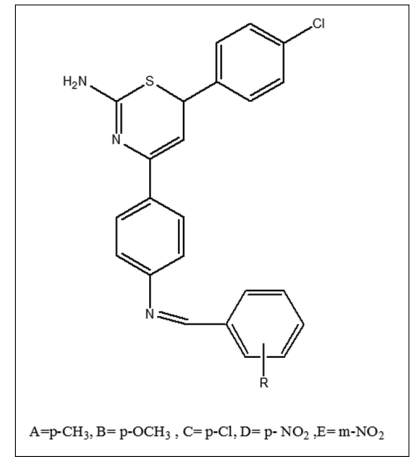

Ghoneim et al. (2015): Antimicrobial activity of the synthesized 1,3-thiazine compound was investigated against pathogenic materials B. subtilis (Gram-positive), E. coli (Gram-negative), and two fungus using the disk diffusion method [17].

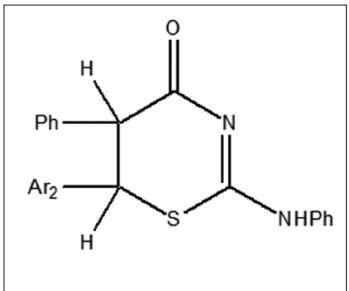

Haider (2012): The compounds (25) were monitored for their antimicrobial activity against bacterial strains $S$. aureus (Gram-positive) and P. aeruginosa (Gram-negative) [18].

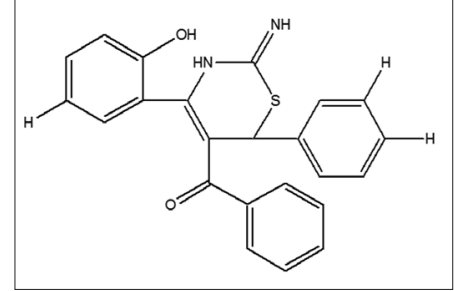

Ghoneim and Bdelaziz (2014): Thiazines mentioned below were tested for biological activities against bacteria $S$. aureus (Gram-positive) and E. coli (Gram-negative) in addition to pathogenic fungi and exhibit good results [19].

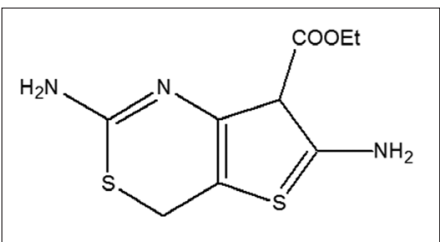

Beena (2013): Thiazine derivatives 27a-e showed antimicrobial activity against all the bacterial microorganisms used for the study [20].

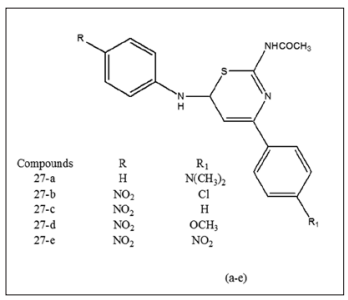

Gayathri and Jacob (2012): Substituted thiazines were screened for their antibacterial activity. Compounds containing electron withdrawing groups in the substituted benzimidazole thiazine were established to show strong antibacterial activities [21].

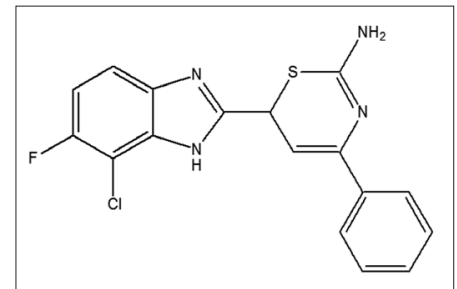

Prakash and Ingarsal (2015): Thiazine derivatives were tested their antimicrobial activities against representative bacterial strains E. coli, B. subtilis, P. aeruginosa, S. aureus, etc., and fungal strains A. niger and Aspergillus flavus [22].

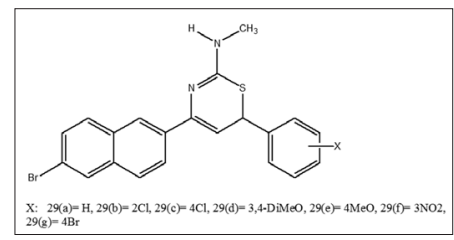

Valliappan (2013): Synthesized compounds were examined in vitro for antimicrobial activity against E. coli (Gram-negative), S. aureus (Gram-positive), Aspergillus fumigatus, and A. niger and shown antimicrobial activities [23]. 


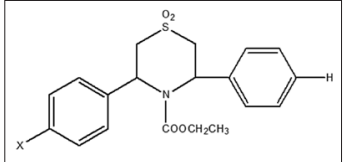

Banda et al. (2012): The compound has been screened for their analgesic and antimicrobial activities. Benzimidazole thiazine was found to show potent analgesic and antibacterial activities [24].

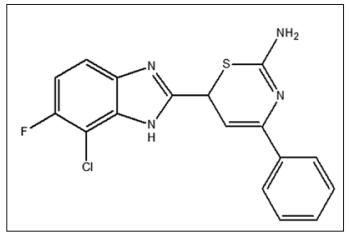

Kadhim (2010): Azachalcone compounds show biological activities against different strains of bacterial and fungi [25].

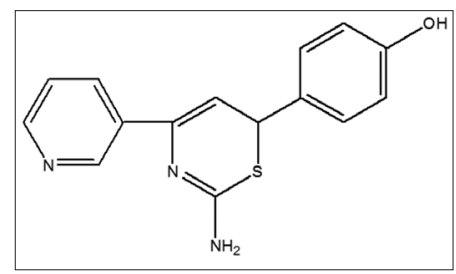

Gahtori and Ghosh (2012): Thiazine derivatives (15) showed moderate to significant susceptibilities toward deferent strains of bacteria [26].

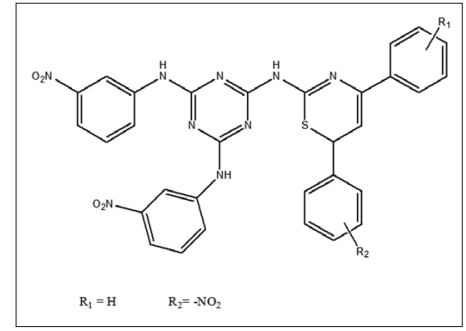

Govindan (2013): Substituted 1, 4-thiazine-1, 1-dioxides were examined for their in vitro antimicrobial activity against Gram-positive and Gram-negative bacterial strains exhibit the strong antimicrobial activities [27].

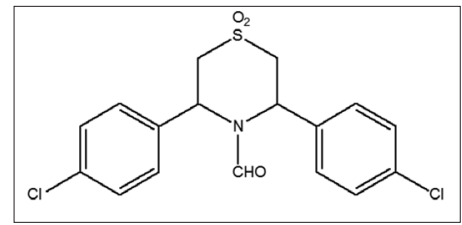

Sharma et al. (2012): Substituted morpholinyl and piperazinyl benzothiazines were examined for antimicrobial activity against and consider as antimicrobial agents [28].

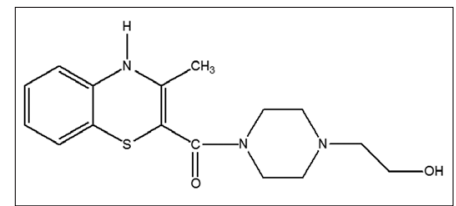

Rathod (2013): Benzothiazines were tested for antimicrobial activities against different bacterial and fungal strains such as E. coli, S. aureus, P. aeruginosa, B. subtilis, Candida albicans, and A. niger [29].
Didwagh et al. (2013): Substituted thiazine derivatives were tested for their antimicrobial activity using ciprofloxacin and fluconazole as standard drugs and shows antimicrobial activities [30].

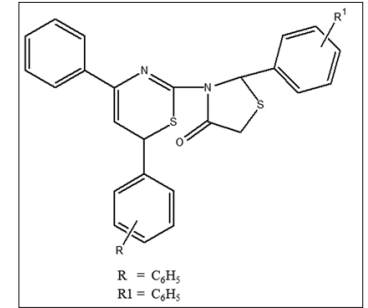

Dabholkar et al. (2013): Substituted benzothiazines were examined for antimicrobial activities against various strains of bacteria such as S. typhi, E. coli, B. substilus, and S. aureus and exhibit antimicrobial activity [31].

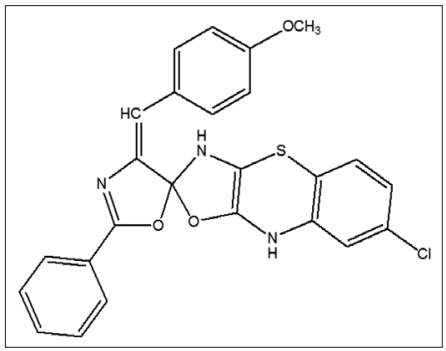

\section{CONCLUSION}

Literature [32-39] revels that thiazines based heterocycles are treated as major group of heterocycles. On the basis of above data, it has been confirmed that a variety of thiazine based heterocycles are believed as probable antimicrobial agents.

\section{REFERENCES}

1. Sharma PK. Morpholinylbenzothiazine consider as bioactive compound. Der Pharm Lett 2016;8(4):86-90.

2. Kumar G, Sharma PK. Synthesis, spectral, energetic and reactivity properties of phenothiazines: Experimental and computational approach. J Chem Pharm Res 2015;7(11):462-73.

3. Sharma PK. Antimicrobial activities of substituted 2-aminobenzothiazoles. J Chem Pharm Res 2015;7(3):819-22.

4. Sharma PK. Synthesis and antimicrobial activities of substituted phenylthioureas. J Chem Pharm Res 2015;7(2):133-9.

5. Sharma PK. Synthesis and antimicrobial studies of fused hetero cycles pyrimidobenzothiazoles. J Chem Pharm Res 2015;7(1):710-4.

6. Sharma PK, Kumar M. Synthesis of bioactive substituted pyrazolylbenzothiazinones. Res Chem Intermed 2015;41(9):6141-8.

7. Sharma PK, Kumar M. Synthesis and antimicrobial activity of 2H-pyrimido [2, 1-b] benzothiazol-2-ones. Res Chem Intermed 2010;36(8):985-93.

8. Sharma PK, Kumar M. One-pot, multicomponent sequential synthesis of benzothiazoloquinazolinones. Synth Commun 2010;40(16):2347-52.

9. Sharma PK, Kumar M. N-bridged bioactive heterocycles: Synthesis of 2-methyl-4H-pyrimido[2,1-b]benzothiazol-4-ones. Res Chem Intermed 2009;35:35-41.

10. Sharma PK, Kumar M. Regioselective one-pot synthesis of 5-chloro-3methyl-8-trifluoromethyl-4H-1,4-benzothiazines. Hetrocycl Commun 2009;15(2):127-33.

11. Sharma PK, Kumar M. Synthesis of 2, 4-diaryl-2, 3-dihydro-1, 5-benzothiazepines. Hetrocycl Commun 2008;14(3):155-60.

12. Ali TE, El-Kazak AM. Synthesis and antimicrobial activity of some new 1, 3-thiazoles, 1, 3, 4-thiadiazoles, 1, 2, 4-triazoles. Eur J Chem 2015;1(1):611.

13. Rathod SP, Rajput PR. Synthesis and antibacterial activities of chlorosubstituted-1, 3-thaizines. Rasayan J Chem 2010;3(2):363-7.

14. Shweta S, Deepika Y. Synthesis and biological activity of phenothiazine derivatives. Int J Res Ayurveda Pharm 2011;2(4):1130-7.

15. Deshmukh R. Synthesis, structural study and biological evaluation of 1 , 3-thiazine. Pelagia Res Library Der Chem Sin 2015;6(3):59-63. 
16. Babu K, Pitchai P. Synthesis and microbial studies of novel 1, 3-thiazine compounds bearing schiff base moiety. Der Pharm Chem 2015;7(10):89-92.

17. Ghoneim AA, Ragab I. Cycloaddition involving activated isothiocyanate: Synthesis and antimicrobial activities of thiazine, pyrimidine and pyridine derivatives. Int $\mathrm{J}$ Chem Pharm Sci 2015;3(4):1637-42.

18. Haider FH. Synthesis and anti-microbial screening of some 1, 3 thiazine derivatives. J Chem Pharm Res 2012;4(4):2263-7.

19. Ghoneim AA, Bdelaziz S. Synthesis and antimicrobial activities of some thieno [3, 2-d] [1, 3] thiazine nucleosides derivatives. Eur J Chem 2014;5(3):397-401.

20. Beena KP. Synthesis, characterization and evaluation of some 1, 3 thiazine derivatives as possible antimicrobial agents. Am J Pharm Tech Res 2013;3(4):2249-3387.

21. Gayathri B, Jacob CM. Microwave assisted synthesis of fluoro, chloro 2 -substituted benzimidazole thiazine derivatives for antibacterial and analgesic activities. Int J Res Pharm Sci 2012;2(3):146-58.

22. Prakash N, Ingarsal N. An efficient synthesis with antimicrobial screening of N-methyl derivative of 4-(2-bromonaphthalen-6-yl)-6aryl-6H-1, 3-thiazin-2-amines. Der Pharm Chem 2015;7(10):246-50.

23. Valliappan R. Synthesis, characterization and biological studies of some 3, 5-diaryltetrahydro-N-ethoxycarbonyl-1, 4-thiazine-1, 1-dioxide. J Appl Chem 2013;2(2):137-42.

24. Banda G, Hipparagi SM, Ramjith US, Jacob CM. The synthesis of thiazine derivatives of fluoro, chloro benzimidazole by the microwave induced reaction and screened for their antibacterial and analgesic activity. Int J Res Pharm Sci 2012;2(3):146-58.

25. Kadhim MA. Synthesis and chemical characterization of some novel azachalcones compounds and evaluation of their biological activity. J Univ Anbar Pure Sci 2010;4(3):40-3.

26. Gahtori P, Ghosh SK. Design, synthesis and SAR exploration of hybrid 4-chlorophenylthiazolyl-s-triazine as potential antimicrobial agents. J Enzyme Inhib Med Chem 2012;27(2):281-93.

27. Govindan S. Synthesis, characterization and biological studies of some 3, 5-diaryl-tetrahydro-N-formyl-1，4-thiazine-1，1-dioxide. J
Chem Pharm Res 2013;5(1):99-103.

28. Sharma PK, Kumar M, Vats S. Synthesis and antimicrobial activity of morpholinyl/piperazinylbenzothiazines. Med Chem Res 2012;21(8):2072-8.

29. Rathod AK. Microwave-assisted synthesis of some new benzothiazines derivatives and their antimicrobial activity. Int J Pharm Sci Rev Res 2013;18(2):47-9.

30. Didwagh SS, Piste PB, Burungale AS, Nalawade AM. Synthesis and antimicrobial evaluation of novel 3-(4, 6-diphenyl-6H-1, 3-thiazin-2-yl)-2-(4-methoxyphenyl) thiazolidin-4-one derivatives. J Appl Pharm Sci 2013;3(11):122.

31. Dabholkar VV, Karekar A, Shinde NB, Naik P. Novel Spiro oxazoles containing triazolothiadiazines, thiadiazines and thiazines - Synthesis, characterization and biological evaluation. J Chem Biol Phys Sci 2013;3(3):1690-6

32. Sharma PK, Kaur C. Antifungal, antibacterial and antioxidant activities of substituted morpholinylbenzothiazine. Der Pharm Lett 2016;8(11):140-2.

33. Sharma PK, Kaur G. Antibacterial, antifungal and antioxidant activities of substituted pyrazolylbenzothiazines. Der Pharm Lett 2016;8(11):79-82

34. Sharma PK. Antibacterial, antifungal and antioxidant activities of substituted 4H-1, 4-benzothiazines. Der Pharm Chem 2016;8(11):156-9.

35. Maheshwari M. A review: Synthesis and medicinal importance of 1 , 4-benzothiazine analogs. Asian J Pharm Clin Res 2015;8(2):41-6.

36. Naruka YS. Antimicrobial activity and characterization of seven synthetic for mamidine disulfide derivatives. Innov J Sci 2016;4(5):1-3.

37. Bhardwaj G. Antibacterial activity in different extracts of Lantana camara against enteropathogens. Innov J Sci 2015;3(1):4-5.

38. Maheshwari M. Synthesis and anti-microbial activity of 1-(6-nitro2h-benzo [b] [1,4] thiazine-3(4h)-ylidene) hydrazine-1, 1-dioxide derivatives. Int J Pharm Pharm Sci 2016;8(10):178-82.

39. Badrey MG. Synthesis and antibacterial activity of fused isoxazole derivatives using grinding method. Int $\mathrm{J}$ Pharm Pharm Sci 2014;6(7):236-9. 